\title{
REVIEW ARTICLE OPEN Qualitative systematic review of barriers and facilitators to self-management of chronic obstructive pulmonary disease: views of patients and healthcare professionals
}

\author{
Siân Russell ${ }^{1}$, Oladapo J. Ogunbayo ${ }^{1}$, James J. Newham ${ }^{2}$, Karen Heslop-Marshall ${ }^{1}$, Paul Netts ${ }^{3}$, Barbara Hanratty ${ }^{1}$, Fiona Beyer ${ }^{1}$ and \\ Eileen Kaner ${ }^{1}$
}

Self-management interventions for chronic obstructive pulmonary disease (COPD) can improve quality of life, reduce hospital admissions, and improve symptoms. However, many factors impede engagement for patients and practitioners. Qualitative research, with its focus on subjective experience, can provide invaluable insights into such factors. Therefore, a systematic review and synthesis of qualitative evidence on COPD self-management from the perspective of patients, carers, and practitioners was conducted. Following a systematic search and screening, 31 studies were appraised and data extracted for analysis. This review found that patients can adapt to COPD; however, learning to self-manage is often a protracted process. Emotional needs are considerable; frustration, depression, and anxiety are common. In addition, patients can face an assortment of losses and limitations on their lifestyle and social interaction. Over time, COPD can consume their existence, reducing motivation. Support from family can prove vital, yet tinged with ambivalence and burden. Practitioners may not have sufficient time, resources, or appropriate skills or confidence to provide effective self-management support, particularly in regard to patients' psychosocial needs. This can compound patients' capability to engage in self-management. For COPD self-management to be effective, patients' psychosocial needs must be prioritised alongside medication and exacerbation management. In addition, patients' personal beliefs regarding COPD and its management should be reviewed periodically to avoid problematic behaviours and enhance positive adaptions to the disease. Patients with COPD are not a homogenous group and no one intervention will prove effective for all. Finally, practitioners require greater education, training, and support to successfully assist patients.

npj Primary Care Respiratory Medicine (2018)28:2 ; doi:10.1038/s41533-017-0069-z

\section{INTRODUCTION}

Chronic obstructive pulmonary disease (COPD) is typically characterised by breathlessness (dyspnoea), chronic airway obstruction, and chronic cough with sputum production. COPD, caused predominately by smoking, is a leading cause of mortality and disability worldwide and represents a socioeconomic burden for developed and developing countries. ${ }^{1}$ Within the UK, COPD is the second largest cause of unplanned hospital admissions ${ }^{2,3}$ and costs the National Health Service approximately $£ 810-£ 930 \mathrm{~m}$ annually. ${ }^{3}$

COPD is incurable. Patients face both acute symptom exacerbations and gradual decline in lung function over time, negatively impacting upon activities of daily living, resulting in depression and anxiety, and reducing health quality of life (HRQoL). ${ }^{4-7}$ Such problems can be compounded by comorbidities (e.g., diabetes, osteoporosis, hypertension, lung cancer). ${ }^{8-10}$ Disease incidence and poor outcomes are associated with socioeconomic deprivation, lower educational attainment, childhood disadvantage, and marginalised communities. ${ }^{11-14}$ As such, COPD can be viewed as socially patterned, and associated with inequality.

It has become accepted that people with chronic conditions should be actively engaged in the self-management of their condition(s). Self-management relates to "an individual's ability to detect and manage symptoms, treatment, physical and psychosocial consequences, and lifestyle changes inherent in living with a chronic condition". ${ }^{15}$ Practitioners can facilitate selfmanagement through strategies of support (e.g., patient education, goal setting). ${ }^{16}$ The "ultimate goals" of COPD self-management, according to Effing et al., are improving and maintaining physical health, lessening the impact of symptoms and impairments, increasing emotional, social, and psychological well-being while creating "effective alliances" with family, practitioners, and community. ${ }^{8}$ Given the broad spectrum of issues that fall under the umbrella of self-management, interventions are wide ranging and heterogeneous in focus and delivery. ${ }^{17-21}$

Recent reviews focusing on the effectiveness of COPD selfmanagement interventions suggest interventions can improve HRQoL and disease symptoms, reducing hospital admissions. ${ }^{17,19,20}$ However, patient engagement can be influenced by structural, disease-related, social, and psychological factors (e.g., short consultations, comorbidities, health literacy, social support, depression, anxiety). ${ }^{22-26}$ The social, emotional, and medical needs of those with COPD are varied and complex, making it a challenging condition to self-manage and support. In their recent and extensive review of COPD self-management interventions, Jordan et al. called for further qualitative work to explore barriers

\footnotetext{
${ }^{1}$ Institute of Health and Society, Newcastle University, Baddiley-Clark Building, Richardson Road, Newcastle upon Tyne NE2 4AX, USA; ${ }^{2}$ Department of Primary Care \& Public Health Sciences, King's College London, London, UK and ${ }^{3}$ NHS Newcastle Gateshead Clinical Commissioning Group, Newcastle upon Tyne, UK Correspondence: Siân Russell (sian.russell@newcastle.ac.uk)
} 


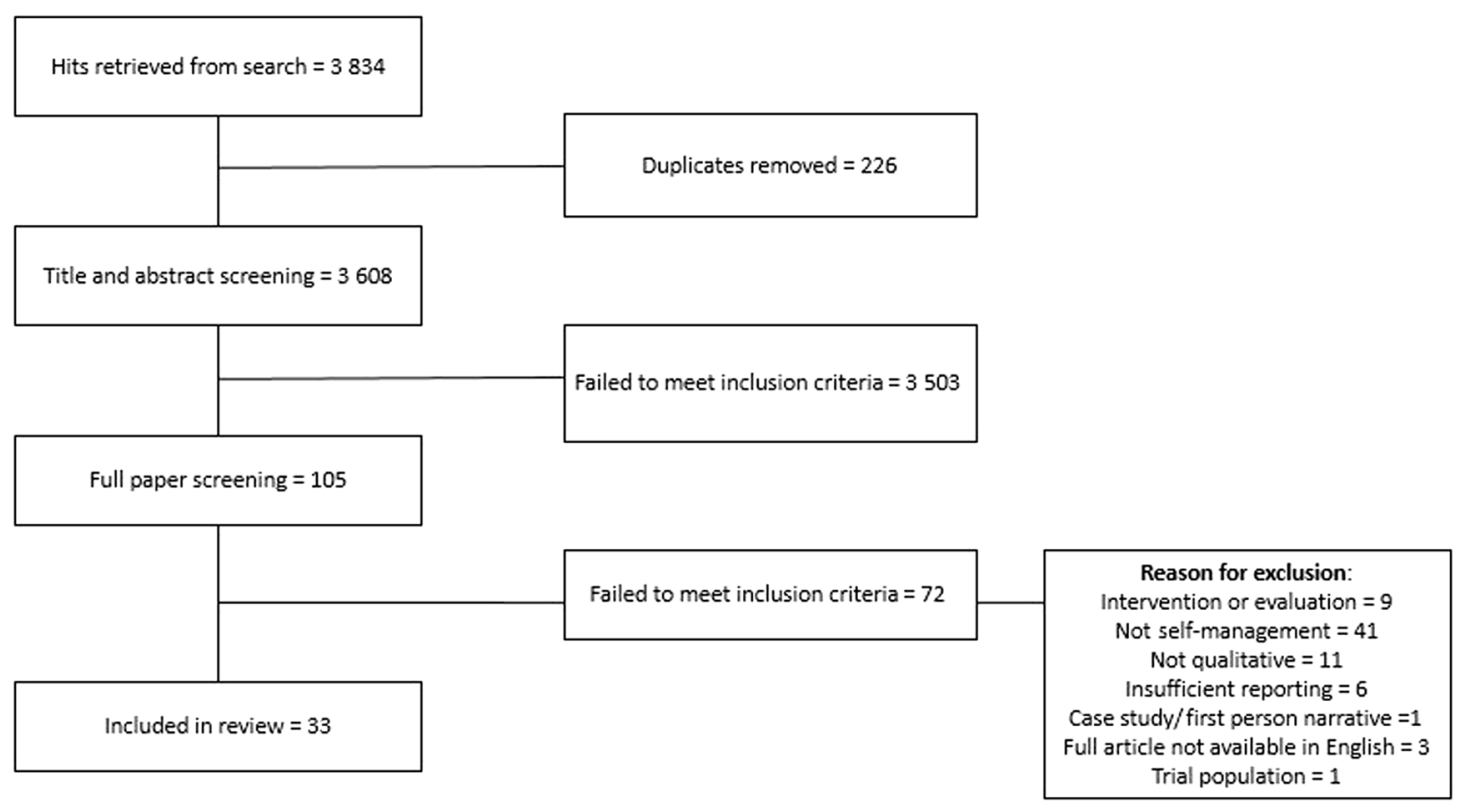

Fig. 1 PRISMA diagram of papers eligible for data extraction

and facilitators to COPD self-management. ${ }^{19}$ Qualitative research, with its focus on subjective experience, is well placed to enhance understanding of such factors, ${ }^{27}$ and enrich guidelines to support improved practice. ${ }^{28}$ This systematic review of qualitative research aims to provide an in-depth insight into the barriers and facilitators to self-management from the perspectives of COPD patients and practitioners involved in the care of COPD patients. It forms part of a wider programme of research exploring COPD selfmanagement from which a meta-analysis and an original qualitative research paper have been published. ${ }^{20,22}$

\section{RESULTS}

The search retrieved 3608 unique articles. Following title and abstract screening 105 were screened on full text, resulting in the exclusion of 72 articles. Of the remaining articles, two by Andersen et al. ${ }^{29,30}$ concerned the same study and two by Chen et al. also reported on one study. ${ }^{31,32}$ In both instances these were analysed as one. The paper by Ogunbayo et al. is from the same research team as this review. ${ }^{22}$ Thus, this review reports on 31 studies. Figure 1 provides a PRISMA diagram of papers eligible for inclusion.

\section{Quality}

The overall quality of the included papers was generally "very good" or "good" (see Table 1) indicating a relatively high-quality body of work.

\section{Overview of included papers}

Included studies were published between 2002 and 2017. Eighteen papers came from Western countries (European countries, North America, Australia, and New Zealand), with only five articles from elsewhere (Iran, Taiwan, Thailand, and Malaysia). Ten papers explicitly referred to self-management within their research aims. The remaining papers referred to selfmanagement elsewhere in the narrative. The majority were interview studies. Thematic analysis, grounded theory, and constant comparison were the most common approaches to data analysis.
Seventeen papers focused on COPD patients, ${ }^{31-47}$ eight on practitioners, ${ }^{22,48-54}$ three on patients and practitioners, ${ }^{55-57}$ three on patients and carers, ${ }^{29,30,58,59}$ and one included all three categories. $^{60}$ The combined population sample included 499 people with COPD, 143 practitioners, and 36 carers.

The mean age of the COPD patients was 69 , calculated from 16 papers where age was specifically reported. Around two-thirds $(62 \%)$ of participants were male, with three studies containing male-only samples. ${ }^{31,42,55}$ Sixteen papers failed to report ethnicity. From the remaining papers, 50\% were Caucasian. Twelve papers did not report comorbidity. Of the five remaining papers the mean number of comorbidities was $4(\min =1 / \max =10)$ (see Table 2$)$.

Practitioner participants included 58 respiratory specialists, 42 GPs, 18 nurses (non-respiratory), 11 allied health professionals, 2 pharmacists, and 25 other professionals (registrars, interns, community matron, and an exercise instructor). Of the seven papers where gender and ethnicity was reported, $82 \%$ of participants were female and $68 \%$ were Caucasian (see Table 3 ).

Data concerning carers was limited. From the papers where gender and relation to participant were reported, the majority were spouses (78\%) and were female (67\%) (see Table 4).

Self-management definitions

Definitions and explanations of self-management across the papers varied. As detailed in Table 5, 10 papers offered no clear definition or explanation, 8 referred to emotional or psychological elements, and 7 highlighted well-being or quality of life. Nineteen papers characterised self-management, at least in part, in terms of tasks, skills, and techniques, self-regulation or self-monitoring. Eleven papers referred to disease knowledge.

\section{Findings}

Below the findings that emerged from the analysis are presented and discussed. For participant quotes the following key applies: $\mathrm{P}$ $=$ Patient, $\mathrm{HP}=$ Healthcare practitioner, $\mathrm{C}=$ Carer .

Knowledge, understanding, beliefs, and communication Patient knowledge and understanding of COPD appeared to be interwoven with the individual's "lifeworld" (subjective sense of 
Table 1. Quality of included papers

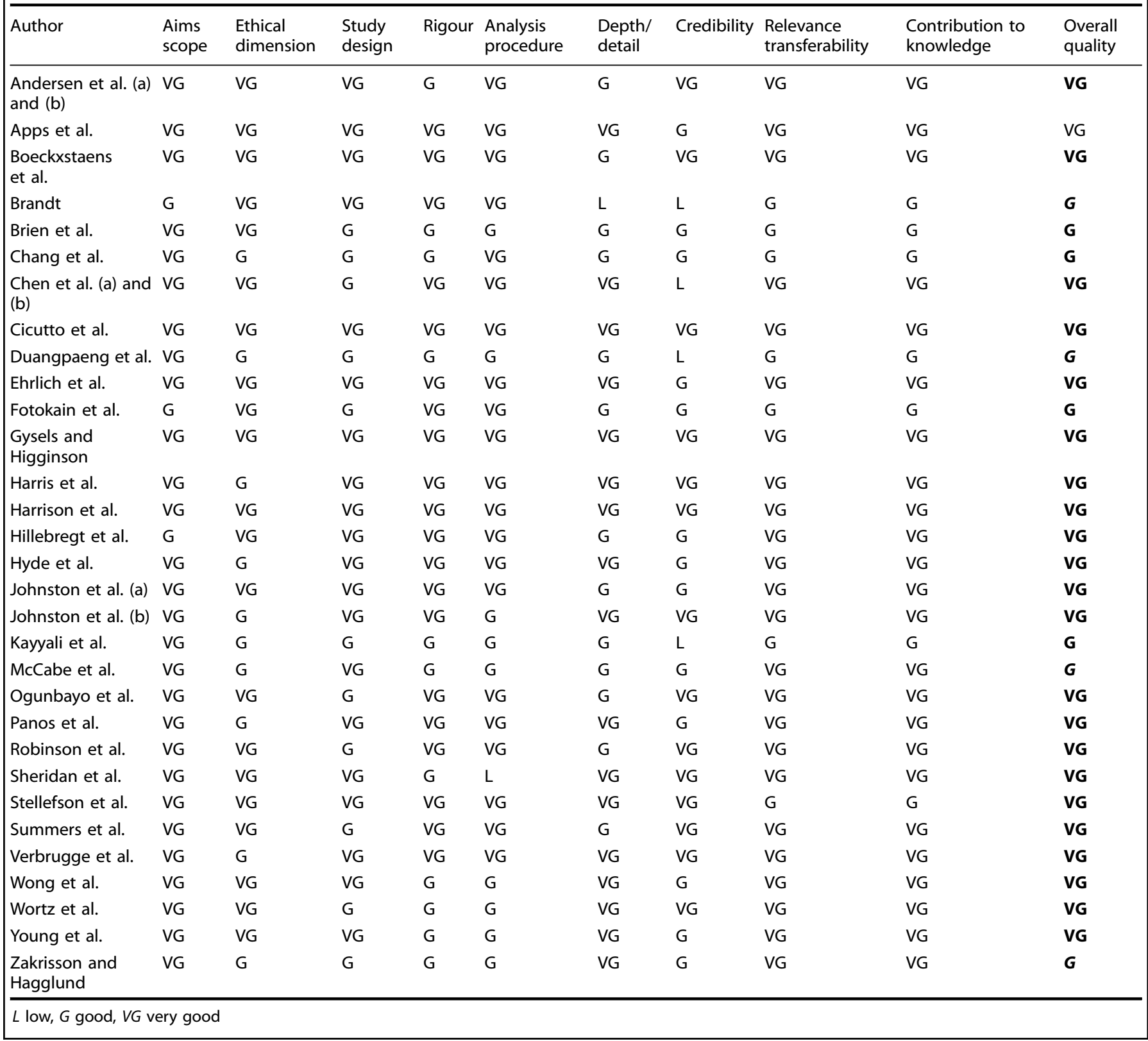

self and the external world, shaped by personal experiences). As Ehrlich reported:

... self-generated intrinsic information and externally available information was processed through an interpretive filter aimed at determining the relevance and plausibility of that information in participants' own lives. ${ }^{37}$

The lifeworld interpretation could be positive, as patients adapted to the condition; however, it also enabled patients to rationalise problematic behaviours such as continuing to smoke or ignoring advice of practitioners. For example, Apps et al. found patients' beliefs about medication could impact upon their adherence to prescribed medications.

I'm not using my inhalers so much ... I might be wrong on this, but I'm thinking if I don't have to use the inhalers too much now, if I get worse, I've still got the inhalers to use before I have to go on the dreaded oxygen. $(P)^{33}$

In addition, patient knowledge of COPD was reported as limited within patient focused papers and by practitioners. Patients failed to understand terminology, conflating COPD with asthma, did not understanding the progressive/incurable nature of COPD, and were confused regarding exercises and how to recognise and respond to exacerbations. ${ }^{3,34,42-45,55,56}$ Family/carers could often fill this gap by taking responsibility for asking questions and implementing information. ${ }^{29,59}$ Lack of understanding or confusion could lead to frustration and have implications for patient's confidence in undertaking self-management activities. ${ }^{33,38,45}$ However, eight studies reported that patients had either received limited or no information from practitioners. $33,38,43-45,55,56,58$ Patients felt frustration due to conflicting information received from different practitioners and external sources, a lack of 
nPj Views of patients and healthcare professionals
S Russell et al.

Table 2. Patient characteristics

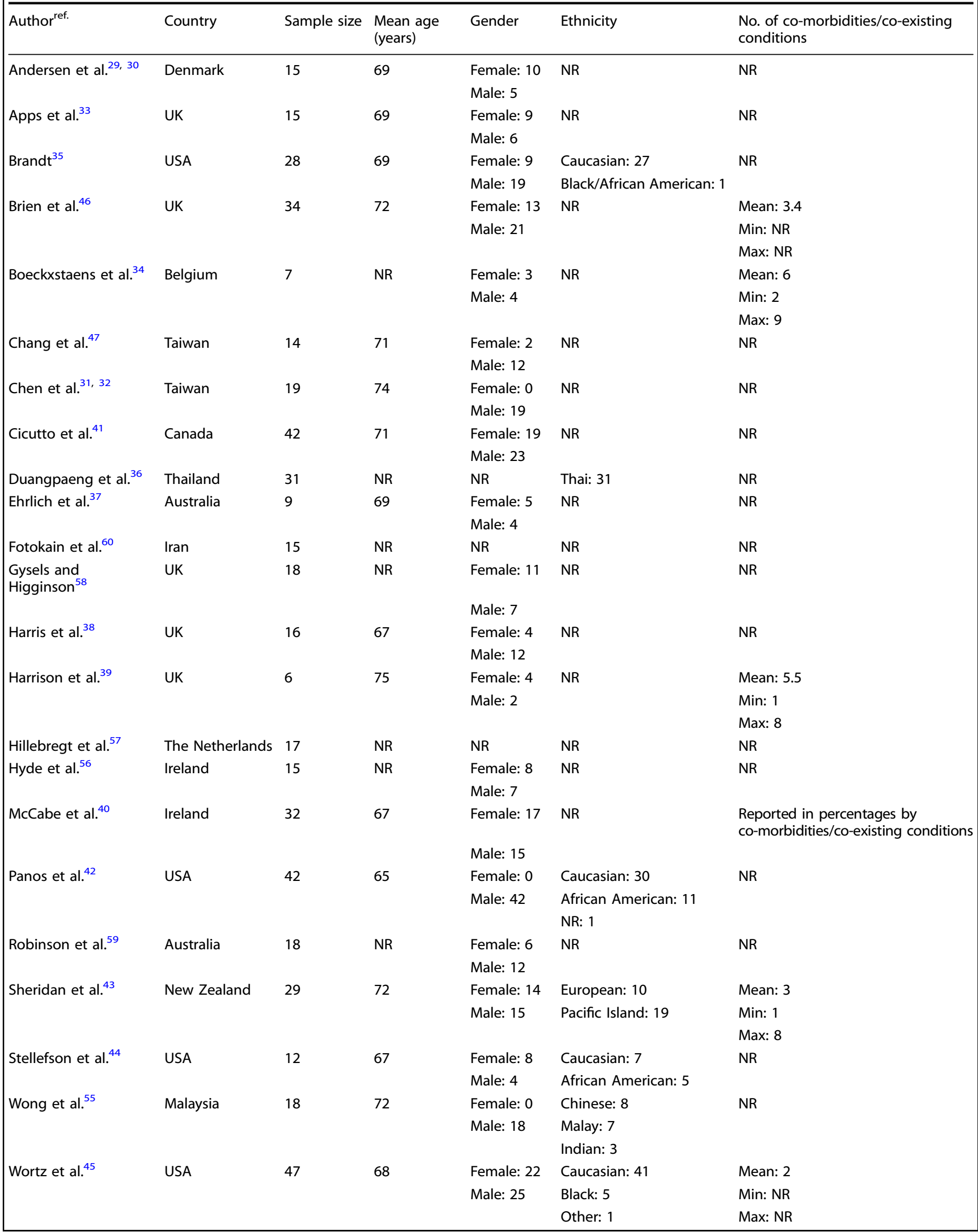




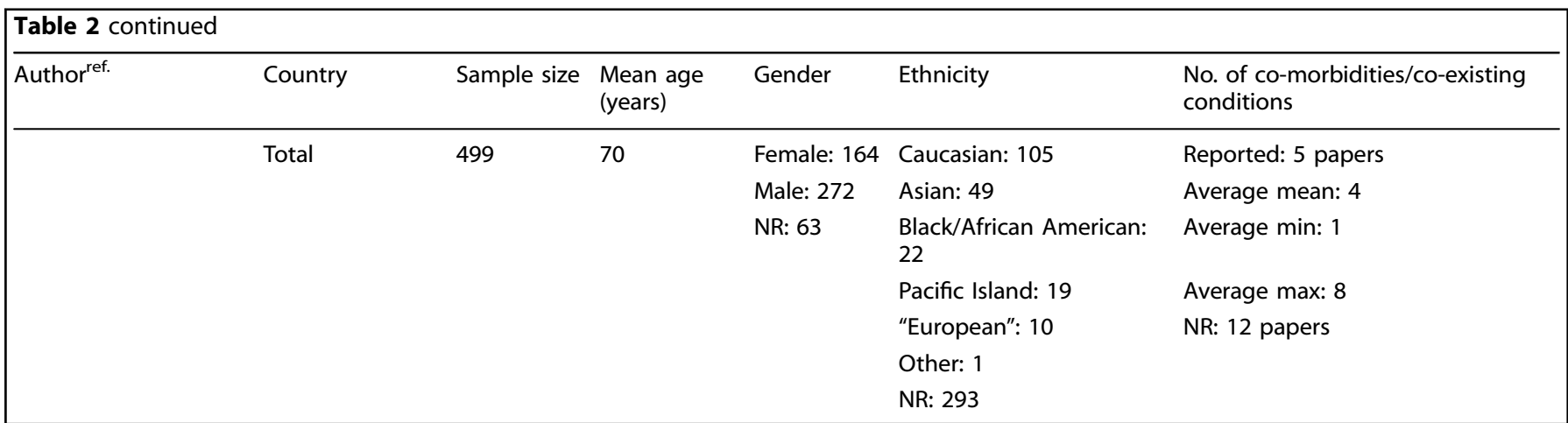

opportunity to ask questions within consultations, and medicine being prioritised over lifestyle concerns. Conversely, practitioners were concerned about patients' confidence, literacy, health literacy, and recall. ${ }^{49,54}$ Practitioners could make assumptions regarding patients ability to understand COPD, resulting in misleading terms such as asthma or "breathing problems" being used. $^{55,56}$

... Should I give him a leaflet? Is that enough? Can the patient read?...How long does he remember it ...? $(\mathrm{HP})^{54}$

A lot of them, they don't even know what is COPD. If symptoms are mainly breathlessness, then it's 'asthma' $(\mathrm{HP})^{55}$

Practitioners understanding of self-management often seemed narrow, focusing on exacerbation and medication, with practitioners being unfamiliar with goal setting and deficient at promoting physical activity, breathing exercises, and good diet. $^{52,56}$ Practitioners' often felt they lacked appropriate knowledge, skills, or education to support self-management, and instead advice focused on adherence to specific behaviours such as smoking cessation and medication. ${ }^{49,56}$ Zakrisson and Hagglund reported that nurses felt a sense an "insufficiency" of skills in health education:

But that [motivational interviewing] is a technique I still haven't really mastered. [...] I find it difficult to steer the interview and simultaneously really reflect what has been said while you still want to get your message across. $(\mathrm{HP})^{51}$

Young et al. reported that many nurses and allied health professionals viewed self-management as outside their daily practice, choosing to refer patients to others for support, highlighting the need for an increased role of pharmacy in selfmanagement. ${ }^{52,54}$ Johnston et al. reported a lack of role clarity regarding pulmonary rehabilitation referrals. ${ }^{48}$ Behaviour change and patient education were viewed as complex, time consuming, and difficult for patients to adopt. ${ }^{48-52,54}$ In addition, communication between different practitioners could be problematic, complicating the care pathway: ${ }^{22,54}$

Communication with other professionals is a challenge. / Different people involved in the care. So it's very complex ... $(\mathrm{HPs})^{54}$

Patient-practitioner relationships

From the patient perspective, practitioners were reported to be important and necessary, and there were some positive interactions, particularly in reference to pulmonary rehabilitation ${ }^{41}$ which was deemed as beneficial for self-management and maintaining exercise. ${ }^{31}$ A multidisciplinary team appeared to be beneficial for providing relevant information (e.g., diet, exercise). However, productive relationships with practitioners could be impeded by: problems of inadequate information; a lack of opportunities to ask questions; feeling rushed by practitioners; a lack of faith in practitioners; lengthy waiting times; or advice that conflicted with patients' perceptions. ${ }^{39,45,55,59}$ Patients could sometimes delay seeking professional support as they wished to avoid hospital or they felt services were too stretched to treat them. ${ }^{39}$ In addition, some did not want to "bother" their $\mathrm{GP}^{35}$ while others believed they could "tough it out" ${ }^{\prime \prime 2}$ or were worried about being judged due to previous or continued smoking..$^{39,56}$ In addition, patients differed across the studies in terms of level of dependence they should have on practitioners or conversely the level of personal responsibility they believe they should take for disease management:

We cannot depend on ourselves. We need someone to treat and give us the medication. That is our routine $(P)^{55}$

[T] here are things that I would do my own thing ... I know my body better. But $I^{\prime} l l$ be guided by the doctors $(P)^{58}$

From the other side of the relationship, older patients were viewed as less motivated and potentially lacking the cognitive skills for self-management and those with comorbidities were also thought to lack motivation. ${ }^{52,54}$ Practitioners often expressed a sense of powerlessness to address behaviour change and a hesitancy to approach patients they believed were resistant, and could feel patient's place responsibility onto them. ${ }^{22,50,52,57}$ However, practitioners also recognised the difficulties patients faced and need to be collaborative and empathetic with patients:

She has got various family problems, money problems, housing problems... In amongst all that ... can't breathe either. It is pulling that big star together of their lifestyle and trying to work out what is going on. $(\mathrm{HP})^{22}$

It's not pleasant to start exercising, for these patients, it's not pleasant for anyone who's unfit to get fit again ... it's much, much worse for them so they need to have that little bit of light at the end of the tunnel, something that they're aiming for [goals]. $(\mathrm{HP})^{53}$

Self-management developing over time

Engaging in self-management activities appeared to go hand-inhand with the length of time living with the condition. Gysels and Higginson ${ }^{58}$ found that: 
Table 3. Practitioner characteristics

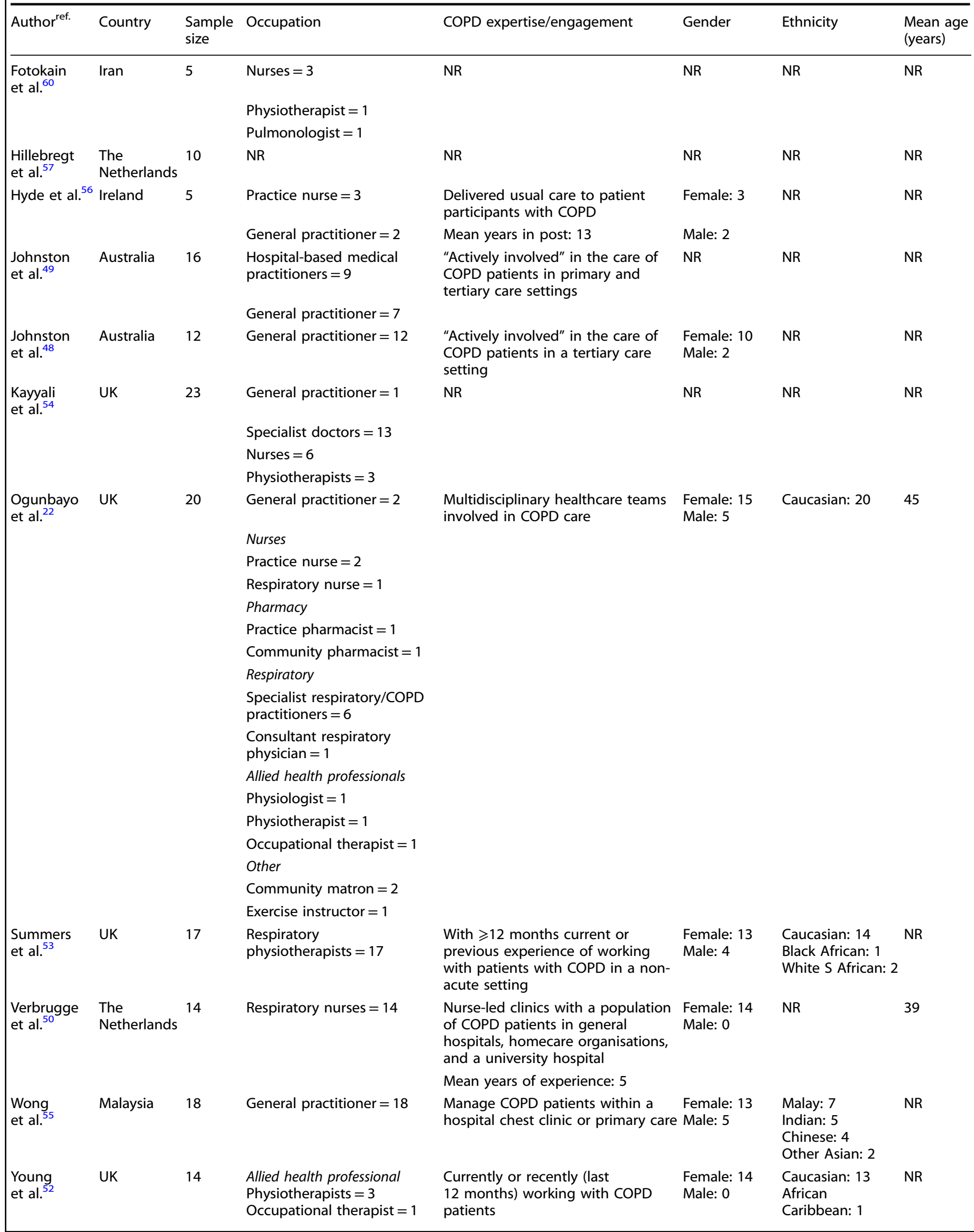




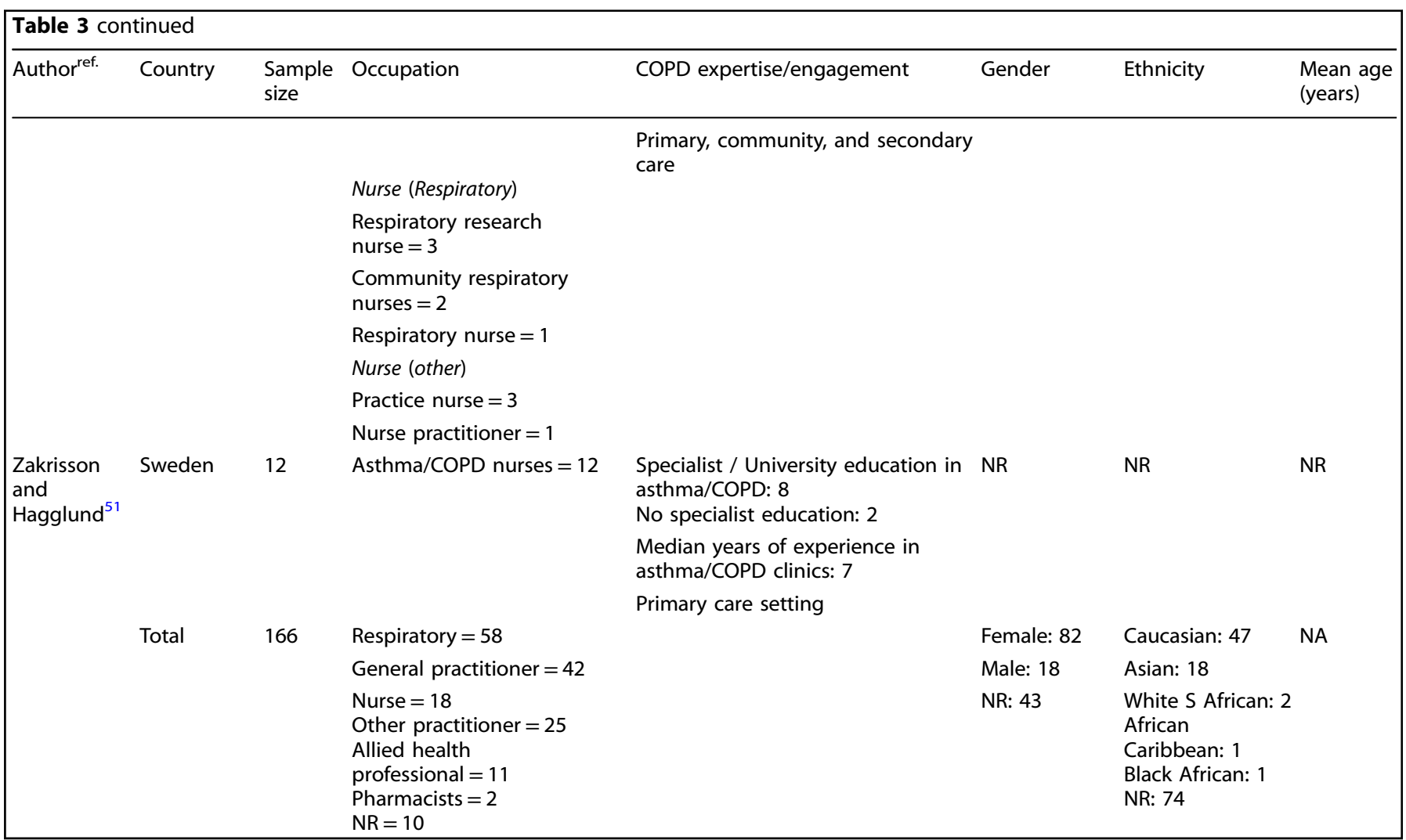

Over time, patients developed an understanding of their symptoms. Previous experiences put recurring sensations into perspective and constant observation of one's physical changes, attention to influences from outside and reactions to self-imposed adjustments or treatments, made some people experts in what happened to their body ${ }^{58}$

This notion of patients becoming experts over time was echoed across other papers and linked with subthemes of trial and error, adaption, and normalisation. ${ }^{33-38,40,41,44}$ Trial and error was a process whereby patients came to recognise what they could no longer do and what they were still capable of doing, and in the course of this process adapted their behaviour to accommodate the condition. This materialised in active self-management behaviours such as allowing more time for activities of daily living and hobbies, reducing or changing the kinds of activities engaged in, planning ahead, and also making changes to the home environment. 31,33-38,40,41,44 While practitioners and the healthcare system were reported to have a role in developing management strategies, patients themselves often undertook this process of adaption without the aid of self-management plans, even when their knowledge of COPD was limited. ${ }^{33,37}$ This revealed an active agency within the population enabling patients to take some control over their condition. By using a "personal filter" ${ }^{\prime 37}$ in interpreting advice and adapting to the condition, COPD could become normalised into patient's lives.

Agency appeared to positively and negatively influence medication use, non-adherence and risk taking behaviour; sometimes in contradiction of medical advice. ${ }^{33,34,37,42}$ For some COPD patients the process of reducing social interaction and slowing down was accepted as an inevitable aspect of the aging process which could help to normalise COPD. ${ }^{33,38}$

Finally, learning to self-manage was often linked to "critical" moments, such as hospitalisation and acute exacerbation episodes that made patients more aware of the consequences of COPD and
Table 4. Carer/family member characteristics

\begin{tabular}{|c|c|c|c|c|}
\hline Author ${ }^{\text {ref. }}$ & Country & Sample size & $\begin{array}{l}\text { Relation to } \\
\text { patient }\end{array}$ & Gender \\
\hline Andersen et al. ${ }^{29}$ & Denmark & 12 & $\begin{array}{l}\text { Spouse: } 8 \\
\text { Daughter: } 4\end{array}$ & $\begin{array}{l}\text { Female: } 9 \\
\text { Male: } 3\end{array}$ \\
\hline $\begin{array}{l}\text { Gysels and } \\
\text { Higginson }^{58}\end{array}$ & UK & 11 & $\begin{array}{l}\text { Spouse: } 10 \\
\text { Daughter: } 1\end{array}$ & NR \\
\hline Fotokain et al..$^{60}$ & Iran & 4 & NR & NR \\
\hline Robinson et al. ${ }^{59}$ & Australia & 9 & NR & $\begin{array}{l}\text { Female: } 5 \\
\text { Male: } 4\end{array}$ \\
\hline & Total & 36 & $\begin{array}{l}\text { Spouse: } 18 \\
\text { Daughter: } 5 \\
\text { NR: } 13\end{array}$ & $\begin{array}{l}\text { Female: } 14 \\
\text { Male: } 7 \\
\text { NR: } 15\end{array}$ \\
\hline
\end{tabular}

how their behaviour could impact upon it (e.g., smoking). Critical events offered learning opportunities due to interactions with different professionals and thus information from different sources. ${ }^{37}$

\section{Social factors}

COPD could impact negatively on social interactions due to reduced function and mobility, embarrassment from symptoms (e.g., phlegm, cough) and fear of breathlessness. ${ }^{39,40,42}$ Such limiting of social interaction could lower mood and impact on motivation to engage in self-management activities. ${ }^{29,30,33,37,39}$

I sit on my own and bore myself to death, so I can just as well smoke myself to death $(P)^{30}$

Family members played a key role in emotionally supporting people with COPD to adapt to the condition and engage in self- 
Table 5. Definitions of self-management

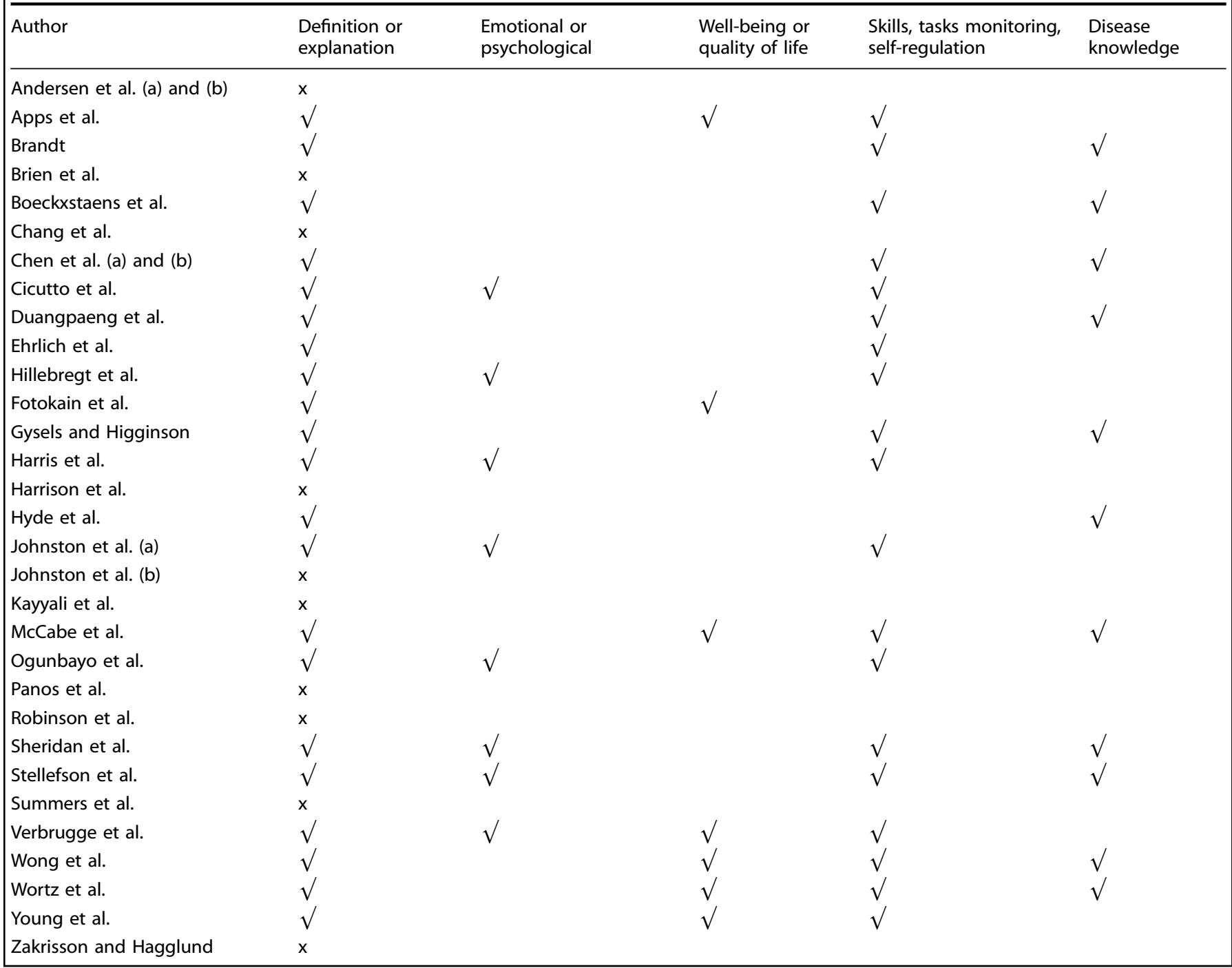

management behaviours. ${ }^{29,33,37,40,41,43,47,59}$ However, the need to rely on family members could result in ambivalence due to guilt and frustration caused by dependence and changes in family roles; ${ }^{10,39}$ exacerbated by the "invisible" nature of the disease:

Because I don't look as though I'm ill, the upsetting thing is that people don't believe you, they think you're putting it on, sometimes even friends and family. $(P)^{33}$

This frustration could go both ways:

... I've been so angry, because he doesn't ask [question] ... he should take a bit of responsibility ... for his own life and health $(\mathrm{C})^{29}$

It's not just affecting him, it's affecting my sleep ... marriage ... children... work $(C)^{59}$

In addition, symptoms could reduce sex and intimacy. ${ }^{42,55}$ This could cause relationship tension:

I was a good husband, but for me to make love to my wife was just, certain parts just couldn't. ... because I just get to where I would (deep breath) like I was going to die and she'd just freak out and then she'd just push me away. $(P)^{42}$

Social comparison to others with COPD, or other peers, could have a positive or negative impact on perception of self and the disease. $^{37,41}$ Interacting with others with COPD, particularly through support groups and pulmonary rehabilitation, offered learning opportunities, a sense of validation of lived experience, and an opportunity to make new friendships. ${ }^{34,37,40,41}$

Sheridan et al., ${ }^{43}$ a New Zealand-based study with a subsample of Pacific Islanders, highlighted that religion or faith could offer a form of support, rationalisation, and acceptance of the condition:

know that it is important for us to pray and keep trying and not just give up, and we are told to wait till death comes. Keep calling our God for his help and wait for his call $(P)^{43}$

Emotional and psychological factors

Anxiety, panic, and fear were commonly reported by patients, and associated with experiencing breathlessness, hospitalisation, as well as fearing a worsening of symptoms and death. ${ }^{30,34-38,40-46,59}$ This was something recognised by family/carers. ${ }^{59}$ People with 
COPD faced considerable loss of functional capacity in their lives resulting in frustration, depression, low mood, and worthlessness. McCabe et al. mentioned that even those who did not state that they were depressed commented on "feeling fed up", "worthless", "thinking of euthanasia", "disappointed", "browned off", "being vexed", "having a lack of motivation", and little "joyfulness". ${ }^{40}$ Such feelings could hinder motivation:

... you can exercise all you want, but if your heart is aching, you're feeling depressed, you'll give up. $(P)^{41}$

However, coming to terms emotionally was deemed important. Humour and determination were both viewed as coping mechanisms:

But you have to make jokes too, don't you! $(P)^{34}$

I will not let it defeat me ... I want to be able to ... keep my quality of life going $(P)^{46}$

The role of smoking in causing lung damage could lead to feelings of guilt, self-blame, and shame. These feelings, plus knowledge of the progressive, incurable nature of the disease, could produce a sense of nihilism or helplessness which adversely impacted upon motivation for self-care and adherence to treatment. ${ }^{39-44}$

The emotional issues such as guilt, low mood, and ambivalence were recognised by practitioners. ${ }^{51,52,55}$ Limited consultation times, and the patients' willingness to disclose and discuss these issues made such support difficult, as exemplified by the excerpts below:

... the emotional part sometimes are not really expressed, because, sometimes we don't have time ... I must say that, actually, they are not coping... but they don't know how to ask for help. $(\mathrm{HP})^{55}$

Loss

Living with COPD, learning to manage it and accommodate it, was greatly associated with a sense of loss and slowing down:

There's a lot of times I can't even make a cup of coffee $(P)^{59}$

Participants reported loss of function, engagement in activities of daily living and hobbies, social ties, independence, family role, and employment. ${ }^{31,33-46,55,56,58}$ Things that could still be engaged in, needed to be done so in a considered and planned manner:

Even squeezing the toothpaste tube, I have to do it deliberately, not like in the old days when I did it. Boop! Finished! $(P)^{36}$

Furthermore, the condition could be all encompassing, defining the lives of those living with it:

it drains you, it absolutely destroys you $(P)^{43}$

... a living death ... it's just a slow death $(P)^{59}$

it eats up your life $(P)^{41}$

Patients could compensate for losses, substituting previous active hobbies with sedentary ones; ${ }^{40,41}$ however, this could be tinged with disappointment. ${ }^{41}$
As far as my activities are concerned uhhh, I can't do anything that I appreciate being able to do before I had this disease ... all that I used to love to do, can't do it now so it's boring, really boring $(P)^{41}$

\section{DISCUSSION}

This review sought to achieve an understanding of barriers and facilitators to COPD self-management from the perspectives of patients and practitioners. Findings suggested that people with COPD are with faced multiple, linked factors which impacted on their ability to engage in self-management, which extended beyond symptom management. For example, while behaviours such as planning ahead and limiting activities could be positive for managing symptoms, such behaviours could also reduce participation and social interaction, resulting in negative emotions and impeded motivation for self-care. Whether something is a barrier or facilitator appeared to be context bound. For instance, families could provide vital emotional and practical support, yet this could instil a sense of guilt or even frustration if support was inadequate. This reflects findings reported elsewhere ${ }^{7,26,61}$ which indicate that factors influencing chronic disease self-management are on a continuum, and can interact, as opposed to being clearly categorised as barriers or facilitators.

Patient's knowledge and understanding of COPD was often reported as limited. COPD diagnosis and poorer outcomes have been associated with lower socioeconomic status and lower educational attainment. ${ }^{11-13,62-64}$ Low health literacy has been associated with higher disease severity, increased helplessness, poor HRQoL, and greater use of emergency healthcare utilisation in COPD patients. ${ }^{65}$ In addition, health literacy influences health beliefs: Kale et al. found that COPD patients with low health literacy were less likely to believe that COPD is incurable, increasingly likely to express concerns regarding possible negative consequences of medications, and to be concerned about their illness and its effects on their emotions. ${ }^{66}$ Promoting enhanced knowledge within the COPD patient population is a highly complex issue which could be compounded by such social patterning. Gaging patients' health literacy status could be a vital aspect of self-management support. Nevertheless, some patients are capable of initiating their own management strategies, even when knowledge and understanding is limited. This is, in part, due to developing an understanding of their condition over time. As such practitioners should aim for ongoing engagement with patients accounting for, and harnessing patients' own illness perceptions and self-learned self-management strategies. ${ }^{33}$ As Effing and colleagues have reported, COPD self-management interventions should be iterative, patient-centred interactions, that account for literary and health literacy focusing on:

1) identifying needs, health beliefs and enhancing intrinsic motivations; 2) eliciting personalised goals; 3) formulating appropriate strategies (e.g. exacerbation management) to achieve these goals; and if required 4) evaluating and readjusting strategies. ${ }^{8}$

Achieving this requires comprehensive training for practitioners across the healthcare system, which our findings suggest, is currently lacking. Some practitioners had a narrow view of selfmanagement, focused on symptom management, and some lacked the awareness, skills and/or confidence to engage with COPD patients beyond established practice and patients could feel that practitioners lead consultations. Such issues are acknowledged in the wider literature. Even when practitioners do recognise wider psychosocial needs, they often lack consultation time to effectively discuss patient concerns, a problem that extra education and training alone would not fully address. ${ }^{61}$ Where 
practitioners recognise patient autonomy they can struggle to reconcile this autonomy with achieving positive medical outcomes and active patient involvement, and can prefer to maintain traditional patient-practitioner boundaries. ${ }^{67}$ Thus there should be a greater focus on interventions that encourage and enable practitioners to cultivate effective ways of engaging with patients, such as shared decision-making. ${ }^{68}$

The emotional and psychological burden of chronic illness is well established. ${ }^{4-7,23,69-73}$ Depression and anxiety are common among people with COPD as are feelings of guilt and stigma due to the perceived self-inflicted nature, and visible aspects of COPD. ${ }^{74-76}$ Family members can help to quell emotional factors; however, some patients may be reluctant to discuss sensitive issues with already burdened carers. Thus a supportive family should not necessarily be viewed as a proxy for emotional support by practitioners; emotional and mental health needs should always be acknowledged and addressed in consultations. In some cases, there may be a need for family-centred self-management interventions to both support patients and help avert feelings of burden, stress, and burnout. ${ }^{77-79}$

COPD patients experience a range of losses and isolation and the condition can seem to consume their existence. Gullick and Stainton theorised that living with breathlessness leads to a "shrinking lifeword", where:

"loss of taken-for-granted breathing increasingly limited the person's self-care abilities, social activities, hobbies and mobility" and "diminishes the predictability and automatic nature of [their] bodies and [their] perceived effectiveness as a person" 10

This speaks to the wider literature on the lived experience of chronic conditions which highlights the potential disruption and change caused to biography and identity. ${ }^{69-73,81}$ Hence there is a need to recognise individuals' identity, history, and lifeworld within the sphere of treatment. ${ }^{72,80}$ Indeed, self-management interventions incorporating behaviour change techniques targeting mental health have been shown to be more effective than those that focus on symptom management alone. ${ }^{17,20}$

There was heterogeneity across the self-management definitions identified in this review. The over-focus on knowledge and skills, and under-focus on emotional factors and HRQoL, is problematic. It is well established that chronic conditions impact upon HRQoL and can present an emotional burden. Addressing these issues must go hand-in-hand with bio-medical disease management (e.g., symptom monitoring, managing medications). ${ }^{8}$ The promotion of holistic and comprehensive descriptions of self-management could help to guide research, policy, and practice (see Effing et al. $^{8}$ ).

\section{Limitations}

This review used robust systematic review methods (e.g., search, screening, extraction, appraisal process) and identified a rich body of relatively high-quality research. Exploring patient, carer, and practitioner accounts also provided a rounded understanding of self-management from multiple perspectives, with clear practice and policy implications.

This qualitative review was limited by the original reporting of data by paper authors and the selection of quotes they used in papers. The female voice was under represented in this literature, and there was little representation of the working age population. Ethnic diversity appeared to be limited; however, this was unclear due to the lack of specific reporting within the papers.

By focusing on self-management within the search, as opposed to the experiences of living with and managing COPD more broadly, this review could have missed relevant sociological and social science literature. However, we searched five key databases, and specifically sought qualitative, multidisciplinary work.

\section{Conclusion and implications}

Living with COPD is a complex, individual experience and thus the ability and capability of people with COPD to engage in successful self-management is dependent on their own personal life context, attitudes, beliefs, emotional responses, socio-cultural resources, and time living with the condition. Primary care and communitybased practitioners are well placed to provide self-management support that is tailored and personalised to patients with whom they often have well-established relationships. ${ }^{82-84}$ Support should be collaborative, addressing how patients conceptualise their condition, the kinds of adaptions they have made to accommodate their condition in order to harness the patient's pre-existing capabilities and motivation, and address wider psychosocial issues.

\section{METHODS}

The review protocol was pre-registered with PROSPERO (CRD42016040169).

\section{Literature identification}

The search strategy (Supplementary Table 1) was designed in collaboration with an experienced information specialist [F.B.], who used thesaurus headings and keywords relating to the COPD and self-management, and translated as appropriate for each database. A multidisciplinary range of databases, most likely to retrieve qualitative research papers, were used. The following databases were searched up to October 2017: MEDLINE (Ovid); ASSIA (ProQuest); CINAHL (EBSCO); Psyclnfo (Ovid); ISI Web of Knowledge. The search was restricted to peer-reviewed articles published in English.

\section{Inclusion and exclusion criteria}

To qualify for inclusion, studies needed to focus on COPD selfmanagement (including where comorbidities were present), from the perspective of patients, their family or carers, and/or practitioners. Studies needed to use qualitative data collection (e.g., focus groups, interviews), analysis, and reporting via narrative data.

Papers were excluded if: (i) there were insufficient or no narrative data to support findings; (ii) there was a focus on intervention outcomes (this review did not aim to compare interventions); (iii) the focus was on behaviour change (e.g., smoking cessation, management of exacerbation) without exploring self-management more broadly; (iv) if participants were experiencing end of life, or palliative care; $(v)$ if the population contained multi-morbidity without a specific focus on COPD.

\section{Screening}

Articles were screened on title and abstract by one researcher [S. R.] and $20 \%$ were independently screened by a second researcher [O.0.]. Articles which met inclusion criteria, or could not be excluded based on the title and abstract alone, were retrieved and checked. Additional researchers [J.N., E.K.] assisted in settling discrepancies.

\section{Quality assessment}

Quality appraisal of qualitative research is a contested issue, partly due to variation in qualitative methodologies and what is considered "good" work within differing approaches. ${ }^{85,86}$ Despite this, assessing quality can prevent unreliable findings from having 
undue influence on the results of a review. ${ }^{87}$ Thus all full-text articles were appraised.

Quality appraisal criteria were adapted from a pre-existing tool focusing on credibility, depth and richness findings, relevance, and whether or not findings are transferable to other settings. ${ }^{88}$ These criteria were assessed on the basis of reporting being judged to be "Very good", "Good", or "Limited" (Supplementary Table 2).

Data extraction and synthesis

Data were extracted by two researchers [S.R., O.O.] (Supplementary Table 3). The wider team supported extraction of factors viewed as barriers or facilitators to self-management. Themes presented by paper authors and data excerpts were compared and contrasted across the body of work, and then grouped and translated into superordinate (higher level) themes via an iterative process, representing cumulative findings. Data excerpts were selected to exemplify our over-arching themes.

\section{ACKNOWLEDGEMENTS}

The authors acknowledge colleagues, Dr. Gregory Maniatopoulos, and Ms. Bethany Bareham for contributing to appraisal tool selection and assisting with data extraction, respectively. The COPD self-management project was funded by the Newcastle Gateshead Clinical Commissioning Group (CCG) research capability funding.

\section{AUTHOR CONTRIBUTIONS}

This review formed part of a wider COPD self-management project. J.N., K.H.M., P.N. E.K., and B.H. were responsible for the conception of this project. F.B. designed and implemented the search in collaboration with S.R. and J.N. O.O. and J.N. assisted with screening, data extraction, and analysis. S.R., an experienced qualitative researcher, with a background in medical sociology, led this review. The initial draft manuscript was written by S.R. All authors provided feedback and agreed with the final version.

\section{ADDITIONAL INFORMATION}

Supplementary information accompanies the paper on the npj Primary Care Respiratory Medicine website (https://doi.org/10.1038/s41533-017-0069-z).

Competing interests: The authors declare no competing financial interests.

Publisher's note: Springer Nature remains neutral with regard to jurisdictional claims in published maps and institutional affiliations.

\section{REFERENCES}

1. Global Initiative for Chronic Obstructive Lung Disease (GOLD). Global strategy for the diagnosis, management, and prevention of chronic obstructive pulmonary disease (2017 Report) (Global Initiative forChronic Obstructive Lung Disease, (GOLD), 2016).

2. Mathers, C. D. \& Loncar, D. Projections of global mortality and burden of disease from 2002 to 2030. PLoS. Med. 3, e442 (2006).

3. National Clinical Guideline Centre. Chronic Obstructive Pulmonary Disease: Management of Chronic Obstructive Pulmonary Disease in Adults in Primary and Secondary Care (National Clinical Guideline Centre, London, 2010).

4. Blakemore, A. et al. Depression and anxiety predict health-related quality of life in chronic obstructive pulmonary disease: systematic review and meta-analysis. Int J. Chron. Obstruct. Pulmon. 9, 501-512 (2014).

5. Heslop-Marshall, K. \& De Soyza, A. Are We Missing Anxiety in People with Chronic Obstructive Pulmonary Disease (COPD)?. Ann. Depress. Anxiety 1, 1023 (2014).

6. Maurer, J. et al. Anxiety and depression in COPD: current understanding, unanswered questions, and research needs. Chest. 134, 43S-56S (2008).

7. Dowson, C. A., Town, G. I., Frampton, C. \& RT., M. Psychopathology and illness beliefs influence COPD self-management. J. Psychosom. Res. 56, 333-340 (2004).

8. Effing, T. W. et al. Definition of a COPD self-management intervention: international expert group consensus. Eur. Respir. J. 48, 46-54 (2016).

9. Barr, R. G. et al. Comorbidities, patient knowledge, and disease management in a national sample of patients with COPD. Am. J. Med. 122, 348-355 (2009).
10. Barnes, P. J. \& Celli, B. R. Systemic manifestations and comorbidities of COPD. Eur. Respir. J. 33, 1165-1185 (2009).

11. Prescott, E. \& Vestbo, J. Socioeconomic status and chronic obstructive pulmonary disease. Thorax 54, 737-741 (1999).

12. Gershon, A. S., Dolmage, T. E., Stephenson, A. \& Jackson, B. Chronic obstructive pulmonary disease and socioeconomic status: a systematic review. J. Chron. Obstruct. Pulmon. Dis. 9, 216-226 (2012).

13. Gershon, A. S., Hwee, J., Charles Victor, J., Wilton, A. S. \& To, T. Trends in socioeconomic status-related differences in mortality among people with chronic obstructive pulmonary disease. Ann. Am. Thorac. Soc. 11, 1195-1202 (2014).

14. Antuni, J. D. \& Barnes, P. J. Evaluation of individuals at risk for COPD: beyond the scope of the global initiative for chronic obstructive lung disease. Chron. Obstr. Pulmon. Dis. 3, 653-667 (2016).

15. Barlow, J., Wright, C., Sheasby, J., Turner, A. \& Hainsworth, J. Self-management approaches for people with chronic conditions: a review. Patient Educ. Couns. 48, 177-187 (2002).

16. Adams, K., Greiner, A. \& Corrigan, J. in Institute of Medicine (US) Committee on the Crossing the Quality Chasm: Next Steps Toward a New Health Care System (eds Adams K., Greiner A.C., \& Corrigan J.M.) (National Academies Press, USA, 2004).

17. Zwerink, M. et al. Self-management for patients with chronic obstructive pulmonary disease. Cochrane Database Syst. Rev. (3), CD002990 (2014).

18. Effing, T. W. et al. Development of a self-treatment approach for patients with COPD and comorbidities: an ongoing learning process. J. Thorac. Dis. 6, 1597-1605 (2014).

19. Jordan, R. E. et al. Supported self-management for patients with moderate to severe chronic obstructive pulmonary disease (COPD): an evidence synthesis and economic analysis. Health Technol. Assess. 19 (2015).

20. Newham, J. J. et al. Features of self-management interventions for people with chronic obstructive pulmonary disease associated with improved health-related quality of life and reduced emergency department visits: a systematic review of reviews with meta-analysis. Int. J. Chron. Obstruct. Pulmon. Dis. 12, 1705-1720 (2017).

21. Majothi, S. et al. Supported self-management for patients with COPD who have recently been discharged from hospital: a systematic review and meta-analysis. Int. J. Chron. Obstruct. Pulmon. Dis. 10, 853-867 (2015).

22. Ogunbayo, $O$. et al. Understanding the factors affecting self-management of COPD from the perspectives of healthcare practitioners: a qualitative study $n p j$ Primary Care Respiratory Medicine 27, 54 (2017).

23. Jerant, A. F. \& Friederichs-Fitzwater M. M.v., \& Moore M. Patients' perceived barriers to active self-management of chronic conditions. Patient Educ. Couns. 57, 300-307 (2005).

24. Coleman, M. T. \& Newton, K. S. Supporting self-management in patients with chronic illness. Am. Fam. Physician 72, 1503-1510 (2005).

25. Disler, R. T., Gallagher, R. D. \& Davidson, P. M. Factors influencing selfmanagement in chronic obstructive pulmonary disease: an integrative review. Int. J. Nurs. Stud. 49, 230-242 (2012).

26. Schulman-Green, D., Jaser, S. S., Park, C. \& Whittemore, R. A metasynthesis of factors affecting self-management of chronic illness. J. Adv. Nurs. 72, 1469-1489 (2016).

27. Oxley, R. \& Macnaughton, J. Inspiring change: humanities and social science insights into the experience and management of breathlessness. Curr. Opin. Support. Palliat. Care 10, 256-261 (2016).

28. Wainwright, M. \& Macnaughton, J. Is a qualitative perspective missing from COPD guidelines?. Lancet Respir. Med. 1, 441-442 (2013).

29. Andersen, I. C. et al. Patients' and their family members' experiences of participation in care following an acute exacerbation in chronic obstructive pulmonary disease: a phenomenological-hermeneutic study. J. Clin. Nurs. 1-13 (2017a).

30. Andersen, I. C. et al. The experience of being a participant in one's own care at discharge and at home, following a severe acute exacerbation in chronic obstructive pulmonary disease: a longitudinal study. Int. J. Qual. Stud. Health WellBeing 12, 1371994 (2017b).

31. Chen, K. H. et al. Self-management behaviours for patients with chronic obstructive pulmonary disease: a qualitative study. J. Adv. Nurs. 64, 595-604 (2008).

32. Chen, K.-H., Liu, C.-Y., Shyu, Y.-I. L. \& Yeh, S.-L. Living with chronic obstructive pulmonary disease: the process of self-managing chronic obstructive pulmonary disease. J. Nurs. Res. 24, 262-271 (2016).

33. Apps, L. D. et al. How do informal self-care strategies evolve among patients with chronic obstructive pulmonary disease managed in primary care? A qualitative study. Int. J. Chron. Obstruct. Pulmon. Dis. 9, 257-263 (2014).

34. Boeckxstaens, P. et al. Chronic obstructive pulmonary disease and comorbidities through the eyes of the patient. Chron 9, 183-191 (2012). 
35. Brandt, C. Study of older adults' use of self-regulation for copd self-management informs an evidence-based patient teaching plan. Rehabil. Nurs. 38, 11-23 (2013).

36. Duangpaeng, S., Eusawas, P., Laungamornlert, S., Gasemgitvatana, S. \& Sritanyarat, W. Chronic dyspnea self-management of Thai adults withCOPD. Thai J. Nurs. Res. 6, 200-216 (2002).

37. Ehrlich, C., St John, W. \& Kendall, E. 'Listening to my body' to 'Look after my body': a theory of information use for self-management of chronic obstructive pulmonary disease. J. Nurs. Healthc. Chronic Illn. 2, 262-270 (2010).

38. Harris, D., Hayter, M. \& Allender, S. Improving the uptake of pulmonary rehabilitation in patients with COPD: qualitative study of experiences and attitudes. $\mathrm{Br}$. J. General. Pract. 58, 703-710 (2008).

39. Harrison, S. et al. "We are not worthy" - understanding why patients decline pulmonary rehabilitation following an acute exacerbation of COPD. Disabil. Rehabil. 37, 750-756 (2015).

40. McCabe, C. et al. Using action research and peer perspectives to develop technology that facilitates behavioral change and self-management in COPD. Int. J. Telemed. Appl. 2014, 380919 (2014)..

41. Cicutto, L., Brooks, D. \& Henderson, K. Self-care issues from the perspective of individuals with chronic obstructive pulmonary disease. Patient Educ. Couns. 55, 168-176 (2004)

42. Panos, R., Krywkowski-Mohn, S., Sherman, S. \& Lach, L. Patient reported determinants of health: a qualitative analysis of veterans with chronic obstructive pulmonary disease. J. Chron. Obstruct. Pulmon. Dis. 10, 333-347 (2013).

43. Sheridan, N. et al. Helplessness, self blame and faith may impact on self management in. J. Chron. Obstruct. Pulmon. Dis. 20, 307 (2011).

44. Stellefson, M., Chaney, B. \& Don Chaney, J. Using exploratory focus groups to inform the development of targeted copd self-management education DVDs for rural patients. Int. J. Telemed. Appl. 2010, 450418 (2010).

45. Wortz, K. et al. A qualitative study of patients' goals and expectations for selfmanagement of COPD. Prim. Care Respir. J. 21, 384-391 (2012).

46. Brien, S. B., Lewith, G. T. \& Thomas, M. Patient coping strategies in COPD across disease severity and quality of life: a qualitative study. NPJ Prim. Care Respir. Med. 26, 16051 (2016).

47. Chang, Y.-Y., Dai, Y.-T., Chien, N.-H. \& Chan, H.-Y. The lived experiences of people with chronic obstructive pulmonary disease: a phenomenological study. J. Nurs. Scholarsh. 48, 466-471 (2016).

48. Johnston, K., Young, M., Grimmer, K., Antic, R. \& Frith, P. Barriers to, and facilitators for, referral to pulmonary rehabilitation in COPD patients from the perspective of Australian general practitioners: a qualitative study. Prim. Care Respir. J. 22, 319-324 (2013).

49. Johnston, K., Young, M., Grimmer-Somers, K., Antic, R. \& Frith, P. Why are some evidence-based care recommendations in chronic obstructive pulmonary disease better implemented than others? Perspectives of medical practitioners. Int. J. Chron. Obstruct. Pulmon. Dis. 6, 659-667 (2011).

50. Verbrugge, R., de Boer, F. \& Georges, J. Strategies used by respiratory nurses to stimulate self-management in patients with COPD. J. Clin. Nurs. 22, 2787-2799 (2013).

51. Zakrisson, A. \& Hägglund, D. The asthma/COPD nurses' experience of educating patients with chronic obstructive pulmonary disease in primary health care. Scand. J. Caring Sci. 24, 147-155 (2010).

52. Young, H. et al. Important, misunderstood, and challenging: a qualitative study of nurses' and allied health professionals' perceptions of implementing selfmanagement for patients with COPD. Int. J. Chron. Obstruct. Pulmon. Dis. 10, 1043-1052 (2015).

53. Summers, R. et al. Giving hope, ticking boxes or securing services? A qualitative study of respiratory physiotherapists' views on goal-setting with people with chronic obstructive pulmonary disease. Clin. Rehabil. 31, 978-991 (2017).

54. Kayyali, R. et al. COPD care delivery pathways in five European Union countries: mapping and health care professionals' perceptions. Int. J. Chron. Obstruct. Pulmon. Dis. 11, 2831-2838 (2016).

55. Wong, S. S. et al. Unmet needs of patients with chronic obstructive pulmonary disease (COPD): a qualitative study on patients and doctors. BMC Fam. Pract. 15, 67-67 (2014).

56. Hyde, N. et al. COPD in primary care settings in Ireland: stories from usual care. $\mathrm{Br}$. J. Community Nurs. 18, 275-282 (2013).

57. Hillebregt, C. F., Vlonk, A. J., Bruijnzeels, M. A., van Schayck, O. C. P. \& Chavannes, N. H. Barriers and facilitators influencing self-management among COPD patients: a mixed methods exploration in primary and affiliated specialist care. Int. J. Chron. Obstruct. Pulmon. Dis. 12, 123-133 (2017).

58. Gysels, M. \& Higginson, I. Self-management for breathlessness in COPD: the role of pulmonary rehabilitation. Chron 6, 133-140 (2009).

59. Robinson, K., Lucas, E., van den Dolder, P. \& Halcomb, E. Living with chronic obstructive pulmonary disease: the stories of frequent attenders to the emergency department. J. Clin. Nurs. https://doi.org/10.1111/jocn.13842 (2017).
60. Fotokain, Z., Mohammadi Shahboulaghi, F., Fallahi-Khoshknab, M. \& Pourhabib, A. The empowerment of elderly patients with chronic obstructive pulmonary disease: managing life with the disease. PLOS ONE 12, e0174028 (2017).

61. Dwarswaard, J., Bakker, E., van Staa, A. \& Boeije, H. Self-management support from the perspective of patients with a chronic condition: a thematic synthesis of qualitative studies. Health Expect. 19, 194-208 (2016).

62. Grigsby, M. et al. Socioeconomic status and COPD among low- and middleincome countries. Int. J. Chron. Obstruct. Pulmon. Dis. 11, 2497-2507 (2016).

63. Gjerdevik, M. et al. The relationship of educational attainment with pulmonary emphysema and airway wall thickness. Ann. Am. Thorac. Soc. 12, 813-820 (2015).

64. Hegewald, M. J. \& Crapo, R. O. Socioeconomic status and lung function. Chest 132, 1608-1614 (2007).

65. Omachi, T. A., Sarkar, U., Yelin, E. H., Blanc, P. D. \& Katz, P. P. Lower health literacy is associated with poorer health status and outcomes in chronic obstructive pulmonary disease. J. General. Intern. Med. 28, 74-81 (2013).

66. Kale, M. et al. The association of health literacy with illness and medication beliefs among patients with chronic obstructive pulmonary disease. PLOS ONE 10 (2015).

67. Dwarswaard, J. \& van de Bovenkamp, H. Self-management support: a qualitative study of ethical dilemmas experienced by nurses. Patient Educ. Couns. 98, 1131-1136 (2015)

68. Elwyn, G. et al. Shared decision making: a model for clinical practice. J. General. Intern. Med. 27, 1361-1367 (2012).

69. Charmaz, K. Identity dilemmas of chronically ill men. Sociol. Q. 35, 269-288 (1994).

70. Charmaz, K. The body, identity, and self: adapting to impairment. Sociol. Q. 4, 657-680 (1995).

71. Bury, M. Chronic illness as biographical disruption. Sociol. Health IIIn. 4, 167-182 (1982).

72. Frank, A. W. The Wounded Storyteller: Body, Illness, and Ethics (University of Chicago Press, Chicago, 1995).

73. Lindsay, S. \& Vrijhoef, H. J. M. A sociological focus on 'expert patients'. Health Sociol. Rev. 18, 139-144 (2009).

74. Ellison, L., Gask, L., Bakerly, N. \& June Roberts, J. Meeting the mental health needs of people with chronic obstructive pulmonary disease: a qualitative study. Chronic IIIn. 8, 308-320 (2012).

75. Johnson, J. L., Campbell, A. C., Bowers, M. \& Nichol, A.-M. Understanding the social consequences of chronic obstructive pulmonary disease. Proc. Am. Thorac. Soc. 4, 680-682 (2007).

76. Lindqvist, G. \& Hallberg L.R.M. 'Feelings of guilt due to self-inflicted disease': a grounded theory of suffering from chronic obstructive pulmonary disease (COPD). J. Health Psychol. 15, 456-466 (2010).

77. Ryan, P. \& Sawin, K.J. The individual and family self-management theory: background and perspectives on context, process, and outcomes. Nurs. Outlook 57, 217-225.e216 (2009).

78. Grady, P. A. \& Gough, L. L. Self-management: a comprehensive approach to management of chronic conditions. Am. J. Public Health 104, e25-e31 (2014).

79. Deek, H. et al. Family-centred approaches to healthcare interventions in chronic diseases in adults: a quantitative systematic review. J. Adv. Nurs. 72, 968-979 (2016).

80. Gullick, J. \& Stainton, M. C. Living with chronic obstructive pulmonary disease: developing conscious body management in a shrinking life-world. J. Adv. Nurs. 64, 605-614 (2008).

81. Charmaz, K. Loss of self: a fundamental form of suffering in the chronically ill. Sociol. Health IIIn. 5, 168-195 (1983).

82. De Silva, D. Evidence: Helping People Help Themselves: A Review of the Evidence Considering Whether it is Worthwhile to Support Self-Management (The Health Foundation, London, 2011).

83. McDonald, V. M., Higgins, I. \& Gibson, P. G. Insight into older peoples' healthcare experiences with managing COPD, asthma, and asthma-COPD overlap. J. Asthma 50, 497-504 (2013).

84. Taylor, S. et al. A rapid synthesis of the evidence on interventions supporting selfmanagement for people with long-term conditions: PRISMS-practical systematic review of self-management support for long-term conditions. Health Serv. Deliv. Res. 2, 1-622 (2014).

85. Dixon-Woods, M., Jones, D., Young, B. \& Sutton, A. Synthesising qualitative and quantitative evidence: a review of possible methods. J. Health Serv. Res. Policy 10, 45-53 (2005).

86. Mays, N. \& Pope, C. Assessing quality in qualitative research. Br. Med. J. 320, 50-52 (2000).

87. Thomas, J. \& Harden, A. Methods for the thematic synthesis of qualitative research in systematic reviews. BMC Med. Res. Methodol. 8, 45-45 (2008).

88. Atkins, S., Launiala, A., Kagaha, A. \& Smith, H. Including mixed methods research in systematic reviews: examples from qualitative syntheses in TB and malaria control. BMC Med. Res. Methodol. 12, 62 (2012). 
Open Access This article is licensed under a Creative Commons Attribution 4.0 International License, which permits use, sharing, adaptation, distribution and reproduction in any medium or format, as long as you give appropriate credit to the original author(s) and the source, provide a link to the Creative Commons license, and indicate if changes were made. The images or other third party material in this article are included in the article's Creative Commons license, unless indicated otherwise in a credit line to the material. If material is not included in the article's Creative Commons license and your intended use is not permitted by statutory regulation or exceeds the permitted use, you will need to obtain permission directly from the copyright holder. To view a copy of this license, visit http://creativecommons. org/licenses/by/4.0/.

(c) The Author(s) 2018 